\title{
Rerefining of Waste Lube Oil via Solvent Extraction Followed by Catalytic Hydrotreatment
}

\author{
H.A. El Sayed, Ebaa A. El-Shamy, Hoda S. Ahmed and \\ Asmaa A. Abd El Rahman \\ Refining Division, Egyptian Petroleum Research Institute, Nasr \\ City, Cairo 11727, Egypt.
}

\begin{abstract}
W
ITH increased time of usage, lubricating oil loses its lubrication properties and thus must be evacuated and a fresh one replaced. Recovery of waste oil is environment friendly and economic. The waste lube oil was treated by $\mathrm{N}$-methyl-2-pyrrolidone (NMP) $+1 \%$ $\mathrm{KOH}$ at different conditions as temperatures from 50 to $70{ }^{0} \mathrm{C}$ and solvent feed ratio from $1 / 1$ to $7 / 1$. The best conditions which produce good quality raffinate with high yield at $70{ }^{\circ} \mathrm{C}$ and solvent feed ratio

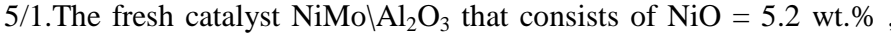
$\mathrm{MoO}_{3}=23 \mathrm{wt}$. $\%, \mathrm{Al}_{2} \mathrm{O}_{3}$ balance was applied for re-refining of the best raffinate at different reaction temperatures range from 320 to $410{ }^{\circ} \mathrm{C}$, hydrogen pressure ranges from 30 to 50 bars and liquid hour space velocity (LHSV) ranges from 0.3 to $0.7 \mathrm{~h}^{-1}$. The best conditions of hydrotreating to produce the high quality lube oil are (temperature $=$ $350{ }^{\circ} \mathrm{C}$, pressure $=50$ bar and LHSV $=0.5 \mathrm{~h}^{-1}$ ).
\end{abstract}

The catalytic tests carried out using both spent and rejuvenated catalyst (using $4 \%$ oxalic $+\mathrm{Fe}\left(\mathrm{NO}_{3}\right)_{3}$ at continuous modes) under the constant temperature, hydrogen pressure and liquid hour space velocity $\left(350{ }^{\circ} \mathrm{C}, 50 \mathrm{bar}, 0.5 \mathrm{~h}-1\right)$ respectively, in order to compare the hydrodesulphurization (HDS) activity of fresh, rejuvenate and spent catalyst. The result indicated that oxalic acid treatment improved the equilibrium HDS activity of the catalyst (nearly close to the equilibrium of fresh), and also improved the quality of waste lube oil.

Keywords: Refining, Used lubricating oil, Solvent extraction and Hydrotreatment.

Lubricating oils are the most valuable constituents in crude oil. Lubricating oil constitutes about $2 \%$ of petroleum derivatives and is one of the few that is not totally consumed during its use ${ }^{(1)}$. Lubricating oils are used to reduce friction and wear by interposing a film of material between rubbing surfaces ${ }^{(2)}$. Lubricants contain about $90 \%$ base oil and less than $10 \%$ additives. The Environmental Protection Agency's definition of waste oil is as follows: waste oil is any oil that has been refined from crude oil or any synthetic oil that has been used and a result of such use is contaminated by physical or chemical impurities ${ }^{(3)}$. Regeneration of waste oil can be beneficial by: (i) Reducing environmental pollution; (ii) Saving foreign exchange for importing virgin lube oils; (iii) Conserving of mineral resources. 
Waste oil can be a very valuable resource, if managed properly. Average crude oils have 3-8 \% base-oil, whereas lube crudes typically have $12-16 \%$ base-oil. This compares with $65-75 \%$ recoverable base-oil content in used automotive oils, which if burnt or dumped would mean the loss of a valuable natural resource. Re-refining of waste oil is energy efficient; less energy (about one third) is used to produce a gallon of base stock from waste oil than to produce the same gallon from crude oil. It is also environment friendly ${ }^{(4)}$. Regeneration of waste oil and associated product markets should be patronized by the government ${ }^{(5)}$.

Among the alternative processes practiced for recycling used lubricating oils during recent years, solvent extraction process has received considerable attention $^{(6-8)}$. This process replaces successfully the classic acid-clay treatment whereby a useful organic sludge is produced instead of the toxic acidic sludge ${ }^{(9)}$. When solvents are added to the waste oil they dissolve the oil and flocculate contaminants like metals, ash, and others ${ }^{(10,11)}$.

The advantage of NMP over other commonly used solvents is: non toxic nature, high solvent power, the easy recovery from solute and high selectivity for aromatic hydrocarbon. NMP can be used for re-refining of waste lube oil with lower sludge, carbonaceous particles and polymer content ${ }^{(12)}$. The addition of potassium hydroxide will increase into solvent, the sludge sedimentation rate where it easily destabilizes the dispersion and increases sludge removal from waste lube oil ${ }^{(2,13)}$. Mild hydrotreating is the key to successful re-refining of used lubricating oils removal; the process produces oils of superior color and with acceptable viscosity. Furthermore, the process provides an operational simplicity, economic feasibility, and environmental attractiveness. This kind of treatment avoids the bleaching clay process, and consequently its disadvantages.

In this work hydrotreatment coupled with solvent extraction. The hydrotreating process has many advantages: Production of a high viscosity index lube oil with a good and stable color and well oxidation resistance; yet has low or no discards ${ }^{(14)}$.

\section{Experimental}

\section{Feedstock}

Waste lubricating oil is kindly supplied from Alexandria Petroleum Company. The characteristics are indicated in Table 1.

\section{Solvent extraction process}

A mixture of solvent (NMP, KOH, $3 \mathrm{gm} / \mathrm{L}$ ) and dehydrated used lubricating oil was subjected to a jacketed mixer settler apparatus for $60 \mathrm{~min}$ at variable conditions. The sludge was allowed to settle down, two phases were separated upper refined oil layer and bottom extract layer \{(mixture of $\mathrm{N}$-methyl 2pyrrolidone (NMP) and oil)\}. The NMP solvent dissolved in raffinate phase was separated by distillation. To determine optimum condition solvent - oil ratio and temperature were varied.

Egypt. J. Chem. 58, No.6 (2015) 
TABLE 1. Properties of waste lube oil (WLO) feedstock.

\begin{tabular}{|c|c|}
\hline Properties & Value \\
\hline Refractive index, $70^{\circ} \mathrm{C}$ & 1.4733 \\
\hline TAN, mg KOH/gm & 0.942 \\
\hline Density, $70^{\circ} \mathrm{C}$ & 0.8652 \\
\hline Flash point, ${ }^{\circ} \mathrm{C}$ & 218 \\
\hline Ash content $\mathrm{Wt} \%$ & 0.61 \\
\hline Carbon residue $\mathrm{Wt} \%$ & 2.57 \\
\hline Pentane insoluble & 6.64 \\
\hline Pour point, ${ }^{\circ} \mathrm{C}$ & -12 \\
\hline Kinematic viscosity, cSt, $40^{\circ} \mathrm{C}$ & 136.5 \\
\hline Kinematic viscosity, cSt, $100{ }^{\circ} \mathrm{C}$ & 14.46 \\
\hline Viscosity index & 105 \\
\hline Sulphur content, wt $\%$ & 0.75 \\
\hline Color & $>8$ \\
\hline Asphaltene, wt $\%$ & 5 \\
\hline Iron, ppm & 24.11 \\
\hline Zinc, $\mathrm{ppm}$ & 44.93 \\
\hline Calcium, ppm & 84.4 \\
\hline ASTM distillation & ASTMD86 \\
\hline IBP & 180 \\
\hline $4 \mathrm{ml}$ & 205 \\
\hline $10 \mathrm{ml}$ & 230 \\
\hline $12 \mathrm{ml}$ & 255 \\
\hline $14 \mathrm{ml}$ & 270 \\
\hline $20 \mathrm{ml}$ & 295 \\
\hline Hydrocarbon, wt $\%$ & \\
\hline Saturate, wt \% & $56 \%$ \\
\hline Aromatic, wt $\%$ & 36 \\
\hline Resin ,wt $\%$ & 8 \\
\hline
\end{tabular}

Extraction variables

A. Extraction temperature: The extraction temperature was $50{ }^{\circ} \mathrm{C}, 60{ }^{0} \mathrm{C}$ and $70{ }^{\circ} \mathrm{C}$ and the settling temperature was $50{ }^{\circ} \mathrm{C}, 60{ }^{\circ} \mathrm{C}$ and $70{ }^{\circ} \mathrm{C}$, respectively for one hour at constant solvent feed ratio of $1: 1$ by weight.

B. Solvent feed ratio : Extraction processes were carried out at various solvent to feed ratios $(1: 1$ to $7: 1))$ at constant extraction temperature of $70{ }^{0} \mathrm{C}$ and settling two hours.

C. Oxalic acid leaching reagent : $4 \%$ oxalic acid solution is prepared with $5 \% \mathrm{H}_{2} \mathrm{O}_{2}$ and $\mathrm{Fe}\left(\mathrm{NO}_{3}\right)_{3}$ as oxidizing agent for the leaching experiments.

- Take 10 gm of the spent catalyst and add the required concentration of the oxidized oxalic acid $(500 \mathrm{ml})$ in $1 \mathrm{~L}$ flask. 
- Heat for $60 \mathrm{~min}$ at $100{ }^{\circ} \mathrm{C}$ with continuous stirring. Finally, after cooling, by filtration, the oxalic acid solution which contains the metal leaching, is reduced to one - third of its original volume. The solid (unfiltered catalyst) is dried in atmosphere, heated at $110{ }^{\circ} \mathrm{C}$ and calcined at $4500 \mathrm{C}$ for $4 \mathrm{hr}$.

The promoter was made of hydrogen peroxide $\left(\mathrm{H}_{2} \mathrm{O}_{2}\right)$; addition was in batch mode only but the promoter (ferric nitrate) addition was varied in two different ways (continuous and batch modes).

In the continuous addition mode, oxalic acid solution was pumped through the catalyst bed and ferric nitrate (promoter) solution was added to the oxalic acid reagent dropwise continuously throughout the run.

In the batch addition experiments, all of the ferric nitrate solution was mixed with the oxalic acid reagent in a single batch at the start of the experiment and the reagent mixture was pumped and recycled through the catalyst bed. The total amount of reagents used and their concentrations were the same in both cases.

\section{Catalyst}

a- Fresh catalyst (Cat: C20 - 7 - 05 TRX) was supplied from Alexandria Petroleum Company and used as hydrotreated catalyst for waste lube oil (that consists of $\left[(\mathrm{NiO}=5.2 \mathrm{wt} \%),\left(\mathrm{MoO}_{3}=23 \mathrm{wt} \%\right)\right.$ and $\left(\mathrm{Al}_{2} \mathrm{O}_{3}\right.$ balance $\left.)\right]$.

b- Spent catalyst, which has been used in re-refining of waste lube oil after 5 years (life time), at Alexandria Petroleum Company. The chemical and physical characteristics of the fresh and spent catalysts are illustrated in Table 2.

TABLE 2. Characteristics of fresh and spent catalysts.

\begin{tabular}{|l|c|c|}
\hline \multicolumn{1}{|c|}{ Characteristics } & $\begin{array}{c}\text { Fresh } \\
\mathbf{N i M o}^{\prime} \mathbf{A l}_{\mathbf{2}} \mathbf{O}_{\mathbf{3}}\end{array}$ & $\begin{array}{c}\text { Spent } \\
\mathbf{N i M o P}_{\mathbf{A l}} \mathbf{O}_{\mathbf{3}}\end{array}$ \\
\hline Chemical compositions $($ wt\%) & & \\
\hline $\mathrm{Mo}$ & 15.01 & 9.58 \\
\hline $\mathrm{Ni}$ & 3.56 & 2.55 \\
\hline $\mathrm{Al}$ & 34.74 & 33.91 \\
$\mathrm{P}$ & - & 10.55 \\
$\mathrm{Ni}$ & - & 4.12 \\
Others & 0.55 & 0.91 \\
\hline Physical characteristics & & 103.6 \\
\hline Surface area, $\mathrm{m}^{2} / \mathrm{g}$ & 186.2 & 0.266 \\
Pore volume, cc/g & 0.4196 & 34.54 \\
\hline Pore radius, $\mathrm{A}^{0}$ & 37.13 & \\
\hline
\end{tabular}




\section{Catalytic activity test}

Catalyst performance tests were carried out in a down flow, high pressure microreactor unit (cata-test unit). The unit consists of a stainless steel reactor (internal diameter $19 \mathrm{~mm}$, external diameter $27 \mathrm{~mm}$, length $50 \mathrm{~cm}$ ), it is divided into three zones, each of them is heated and separately temperature controlled. $100 \mathrm{ml}$ of the catalyst are charged in the middle zone of the reactor.

The catalytic activity experiments are carried out under the operating conditions illustrated in Table 3.

The most important properties of feedstock, raffinate of extraction and products of hydrotreatment are measured using the standard methods indicated in Table 4.

TABLE 3. Catalytic activity operating conditions.

\begin{tabular}{|c|c|}
\hline Conditions & Description \\
\hline Reaction temperature, ${ }^{0} \mathrm{C}$ & $320,350,380,410$ \\
\hline Total hydrogen pressure, bar & $30,50,70$ \\
\hline LHSV, $h^{-1}$ & $0.3,0.5,0.7$ \\
\hline $\mathrm{H}_{2} /$ Feed ratio, $\mathrm{L} / \mathrm{L}$ & 300 \\
\hline Catalyst volume, $\mathrm{ml}$ & 100 \\
\hline Charge stock & Extracted lube oil \\
\hline Catalyst type & Fresh \\
\hline
\end{tabular}

TABLE 4. Standard method (ASTM).

\begin{tabular}{|l|l|}
\hline \multicolumn{1}{|c|}{ Refractive index } & \multicolumn{1}{c|}{ ASTM-D1747 } \\
\hline Density & Mataller Toled-DE40 \\
\hline Kinematic viscosity & ASTM-D445 \\
\hline Viscosity index & ASTM-D2270-98 \\
\hline Sulphur content, X-ray sulfur spectrophotometer & ASTM-D4294 \\
\hline Pour point & ASTM-D97 \\
Ash content & ASTM-D482 \\
\hline Flash point & ASTM-D92 \\
Carbon residue & ASTM-D527 \\
\hline Color & ASTM-D156 \\
\hline
\end{tabular}

\section{Results and Discussion}

A dehydrated waste lube oil of an initial boiling point $\left(180{ }^{\circ} \mathrm{C}\right)$ was conducted from Alexandria Petroleum Company. The physico-chemical characteristics and hydrocarbon component analysis are presented in Table 1 . The given data show that the waste lube oil has lower oxidation stability owing to its high total acid number (0.942 $\mathrm{mg} \mathrm{KOH} / \mathrm{gm})$. Waste lube oil is of high aromatic content reaches to $36 \mathrm{wt}$, \% 
as well as a sulphur compound content of $0.75 \mathrm{wt} \%$. These undesirable constituents are the main reason behind the low oxidation stability. Waste lube oil has high ash content and carbon residue of $0.61 \mathrm{wt} . \%$ and $2.57 \mathrm{wt}$. \% respectively which is considered to reflect oil additive residues and other sources such as wearing and solid residues which leave more residue deposits when evaporated after being subjected to the heat of an engine. Waste lube oil had high percent of different metals as shown in Table 1, such as iron, calcium and zinc also found in waste oil as a result of the virgin oil additives, which were used to improve the properties of the final oil. The viscosity index of the waste oil was found to be 105, which is due to the degradation of the majority of the viscosity index improver through usage; however some of this improver remains unchanged. The waste oil had a low flash point of $218{ }^{0} \mathrm{C}$ due to the decomposition of some of the base oil to light products. Dark and opaque color is attributed mainly to the presence of carbonaceous materials, the different additive types, condensable and oxidizable hydrocarbons and non-hydrocarbons as oxygen, nitrogen, metals and sulphur compounds.

Various techniques have been used in this study to regenerate the waste lube oil. These treatments are:

*Solvent treatment (physical refining) which removes undesirable materials.

*Hydrotreatment, which converts the undesirable materials to desirable one.

\section{Solvent treatment (Extraction)}

Extraction has been carried out for the studied hydrated waste lube oil in this work by using N-methyl 2-pyrrolidone.

Oxidation products have a boiling temperature range similar to that of the base oil and represent a problem since they cannot be separated by distillation ${ }^{(15)}$.

To overcome this proplem, very low quantities of strong base $(\mathrm{KOH}, 3 \mathrm{gm} / \mathrm{L})$ have been added to the solvent. It has caused the elimination of the major part of the oxidation products and metallic compounds. Removal of the oxidation compounds occurs due to the effect of $\mathrm{KOH}$ which neutralizes the acid compounds and induces their saponification and subsequent precipitation. The $(-\mathrm{OH})$ group of the potassium hydroxide breaks the hydrogen bonds between the polar impurities and the dispersant detergent additives of the waste oil.

Extraction variables had been studied in order to control the degree of extraction and the selectivity of the process. These are extraction temperature and solvent feed ratio.

\section{Extraction temperature}

Extraction temperature is considered as one of the most effective extraction variables. The dissolving action of the solvent increases with temperature up to complete miscibility; hence the solvent selectivity is greatly infulenced The extraction temprature is governed by solvent stability and the initial boiling point of feedstock.

Egypt. J. Chem. 58, No.6 (2015) 
Extraction was carried out using NMP associated with $\mathrm{KOH} 3 \mathrm{gm} / 1$ at constant solvent feed ratio of $1: 1$ by weight and at different temperatures from $50{ }^{\circ} \mathrm{C}$ to 70 ${ }^{0} \mathrm{C}$ to optimize the temperature which can give the highest yield with the best quality of raffinate (refined product).

The effect of extraction temperature on the yield and sulphur of the raffinates is shown graphically in Fig.1. The yield of lub oil, sulphur content, total acid number (TAN), refractive index and density content decrease as extraction temperature increased as shown in Fig. 1 ( $a, b$ and c) and the decrease may be attributed to the removal of highly polar aromatic components by the extraction stage ${ }^{(16)}$.
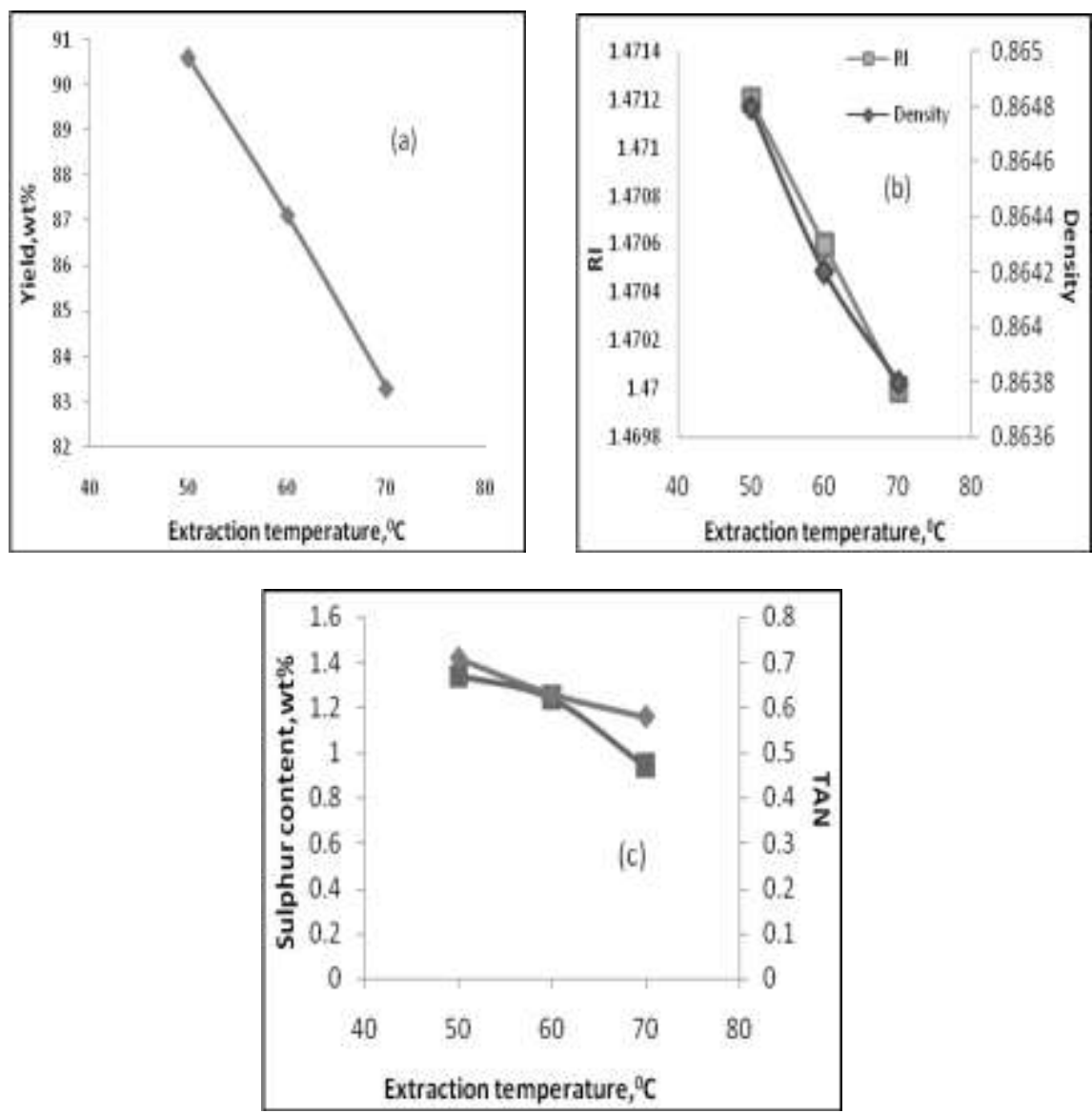

Fig. 1. Effect of extraction temperature on (a) yield, (b) density, refractive index and (c) total acid number, sulphur content.

Figure 2 shows that the inflation of the extraction temperature had increased the viscosity index of the raffinate sharply up to $60^{\circ} \mathrm{C}$ while slightly increased at $70^{\circ} \mathrm{C}$. 
The refining effectiveness number (REN) is considered to be a good measure of the attainable refining effect, i.e. the lower is REN the better is the solvent efficiency. Taking the viscosity index change as the refining performance parameter and by applying this to the present investigation (Fig. 2, a and b), it can be observed that the most suitable extraction temperature is $70{ }^{\circ} \mathrm{C}$ at which $\mathrm{REN}=3.34^{(17)}$
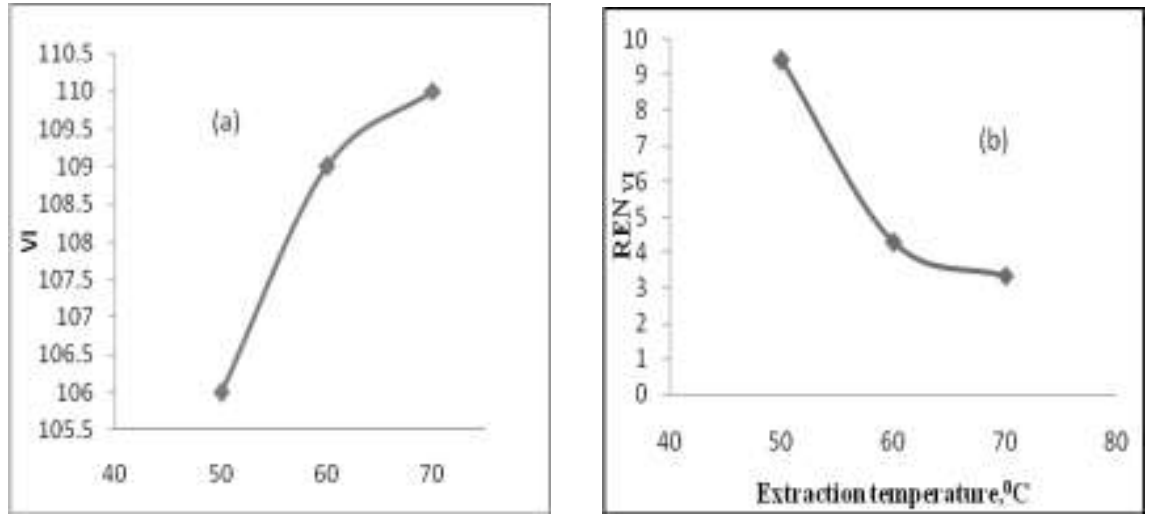

Fig. 2. Effect of extraction temperature on (a) viscosity index and (b) refining effectiveness number .

\section{Solvent feed ratio}

Extraction has been carried out at various solvent feed ratios and extraction temperature of $70{ }^{\circ} \mathrm{C}$ to determine the optimum solvent ratio.

Solvent feed ratio has an obvious effect upon the yield and characteristics of the raffinates. The low yield of the raffinate was accompanied by better quality of the product. The yield of raffinate decreases by increasing the solvent-to-feed ratio due to the increase of the solvent power (Fig. 3a).

The decrease in carbon residue, contents of sulphur and ash and pentane insoluble by increasing solvent feed ratio may be attributed to the removal of the more aromatic components by the extraction process (Fig. $4 \mathrm{a}, 5 \mathrm{~b}$ and $3 \mathrm{c}$ ).

The decrease of the refractive index, density and the sulphur content with increasing solvent feed ratio confirms the prior findings (Fig. 5a \& 5b).

The increase of the solvent feed ratio improves the raffinate quality in term of increasing the viscosity index of the raffinates (Fig. 3b). Also, increasing percentage of removal of acids, ash and pentane insoluble component with increasing solvent feed ratio, (Fig. 4b), confirms the improvement of quality of raffinate. 
The oxidation products of the organic and organo metallic compounds results from the oxidation of additive contaminants which lead to the increase in total acidity of the waste oil decreasing by increasing solvent feed ratio (Fig.4b). This may be due to the increasing of solvent efficiency.

The data of refining effectiveness number (REN) show that the solvent feed ratio of 5/1equal to 1.83 will be quite adequate for extraction of waste oil as in Fig. 5c.

The best raffinate (at $\mathrm{S} / \mathrm{F} 5 / 1 \&$ temp, $70{ }^{0} \mathrm{C}$ ) was used as a starting base material for producing lube oil via catalytic hydrogenation, with using fresh $\mathrm{NiMo} \backslash \mathrm{Al}_{2} \mathrm{O}_{3}$ catalyst.
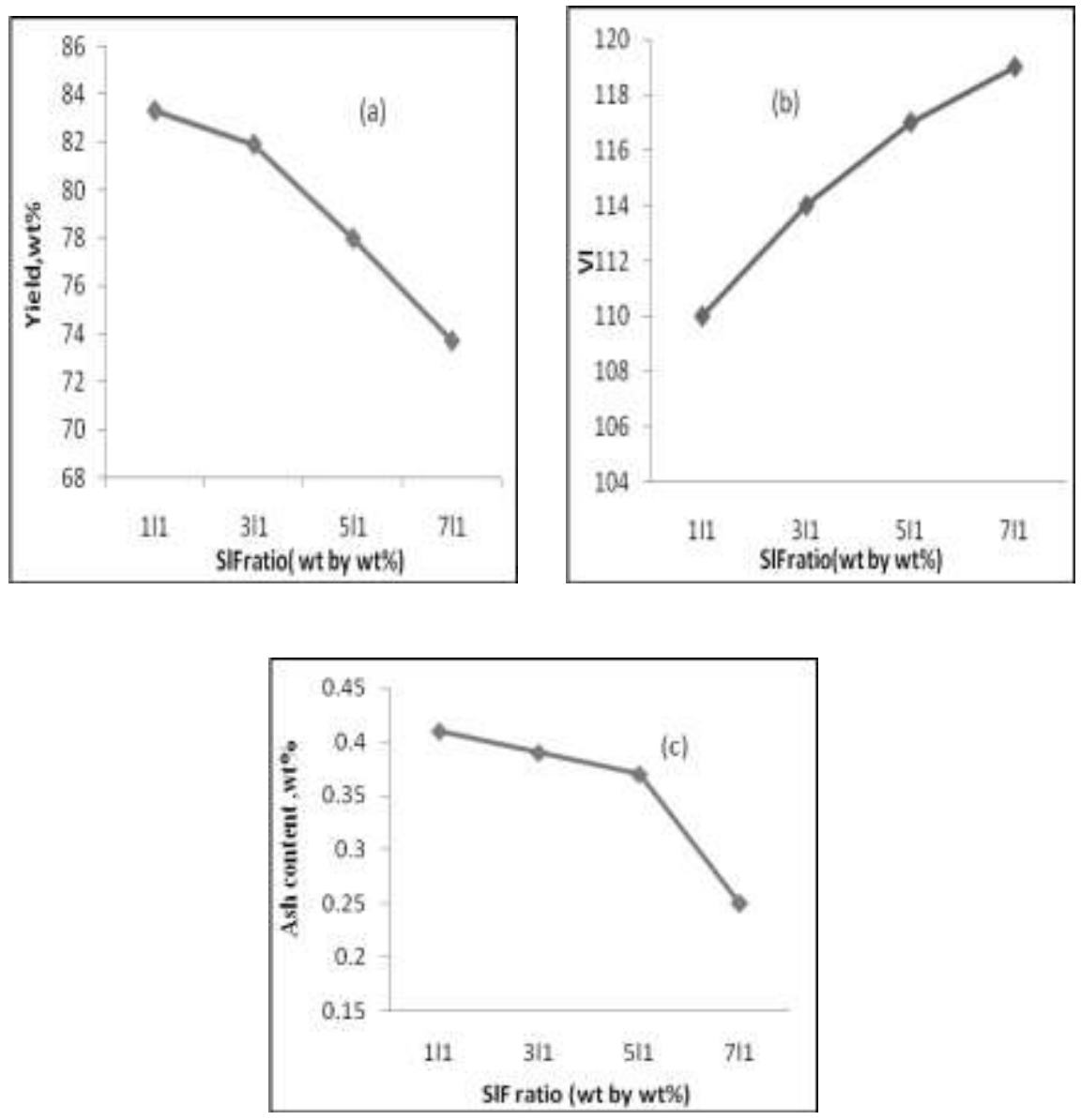

Fig. 3. Effect of solvent feed ratio on yield, viscosity indexand ash content. 

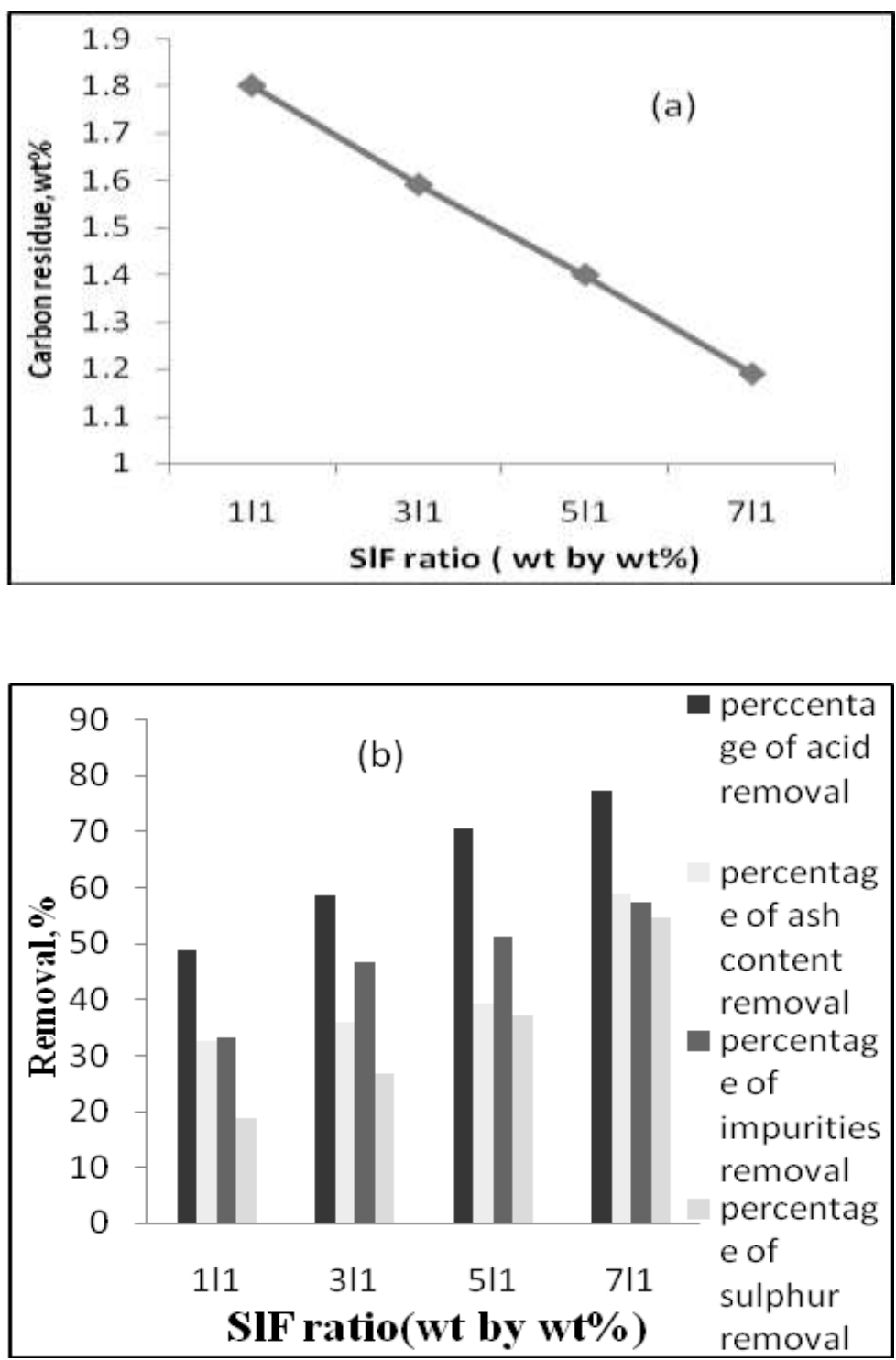

Fig. 4. Effect of solvent feed ratio on (a) carbon residue (b) removal ofacids, ash, impurities and sulphur. 

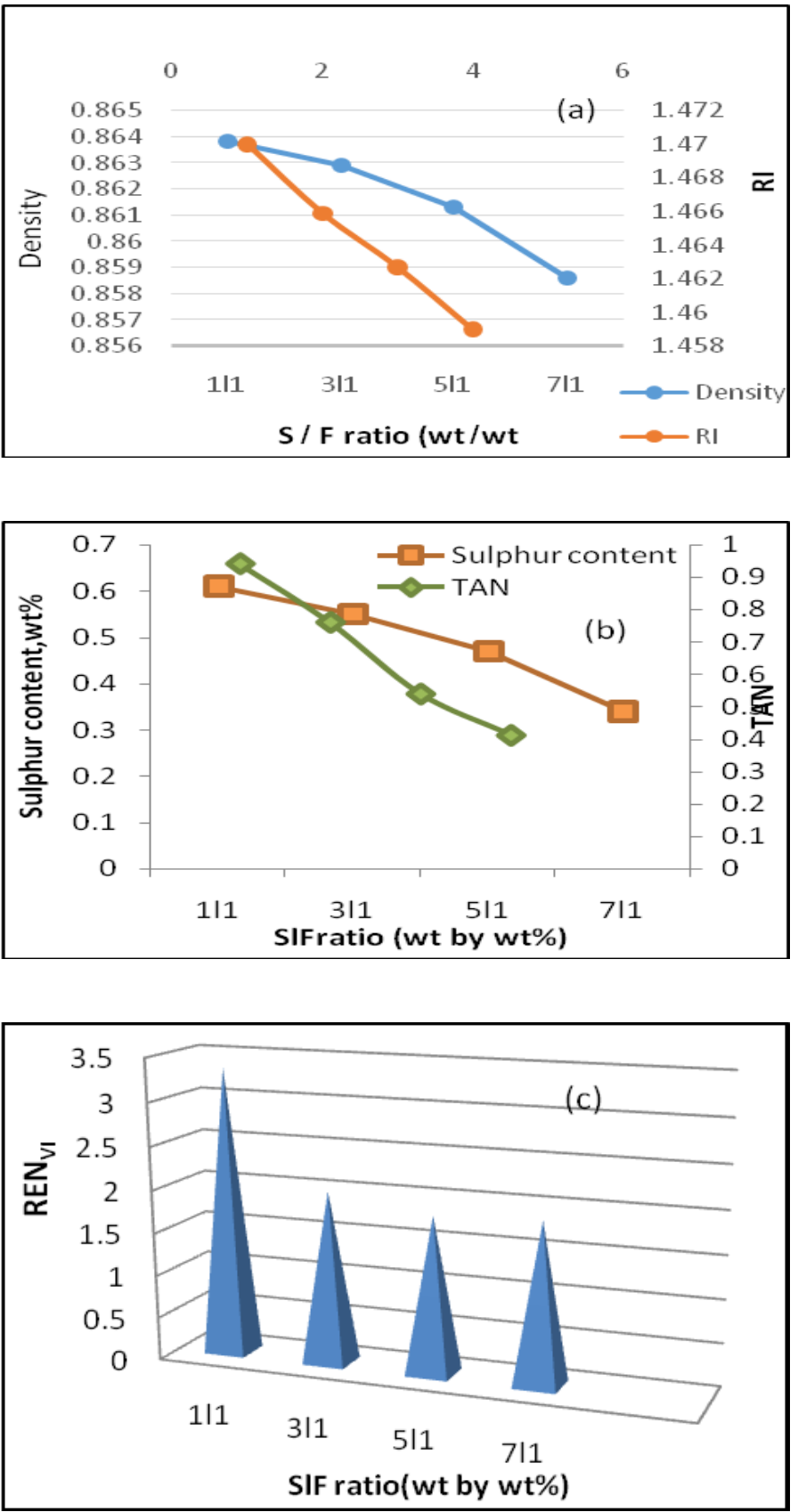

Fig. 5. Effect of solvent feed ratio on (a) density, refractive index (b) total acid number, sulphur(c) refining effectiveness number.

Egypt. J. Chem. 58, No.6 (2015) 


\section{Hydrotreating treatment}

Effect of operating conditions on hydrotreating of waste lube oil

The hydrotreating process of the base stock was carried out in a dynamic phase at different reaction temperature $\left(320^{\circ} \mathrm{C}-410^{\circ} \mathrm{C}\right)$, hydrogen pressure $(30-$ $70 \mathrm{bar})$ and liquid hourly space velocity $\left(0.3-0.7 \mathrm{~h}^{-1}\right)$.

1. Effect of reaction temperature : The results of Fig. 6 and 7 represent the effect of reaction temperature on the yield and product quality. It was shown that the yield of treated waste lube oil was clearly affected by reaction temperature, i.e. decreased as the reaction temperature increased, also the total acid number decreased from 2.5 at $320{ }^{\circ} \mathrm{C}$ to 0.1687 at $410{ }^{\circ} \mathrm{C}$.

As the reaction temperature increased the aromatic content decreased from $33.5 \%$ at $320^{\circ} \mathrm{C}$ to $19.3 \%$ at $410^{\circ} \mathrm{C}$, at the same time. On the other hand, the total saturate content increased from $60 \%$ at $320^{\circ} \mathrm{C}$ to $78 \%$ at $410^{\circ} \mathrm{C}$, this is due to the increase in hydrogenation activity.

Resin was decreased from 7.4 to 2.7 wt.\% with increasing reaction temperature. This can be attributed to the decomposition of resin which is present in the feed to coke reported ${ }^{(18)}$.

The partial hydrogenation of cyclic and, heterocyclic aromatics, followed by splitting of sulphur and oxygen bonds had liberated the sulphur as $\mathrm{H}_{2} \mathrm{~S}$ and removed the oxygen from the organo metallic oxygenated and acid components. A drop in the value of sulphur content and total acid number is in agreement with this interpretation. The splitting of sulphur and oxygen bond lead to the removal of about 65.62 and $88.2 \%$ of the total sulphur and from 73.46 to 97.98 of the total acid number respectively at $320{ }^{\circ} \mathrm{C}$ and $410{ }^{\circ} \mathrm{C}$.

Viscosity index was improved and increased from 128 at $320{ }^{\circ} \mathrm{C}$ to 130 at $410{ }^{\circ} \mathrm{C}$. The color of the oil became lighter by increasing reaction temperature, and the amount of pentane insoluble compounds decreased by increasing temperature from $320^{\circ} \mathrm{C}$ to $410^{\circ} \mathrm{C}$. Generally the quality of the treated waste lube oil was improved by increasing temperature.
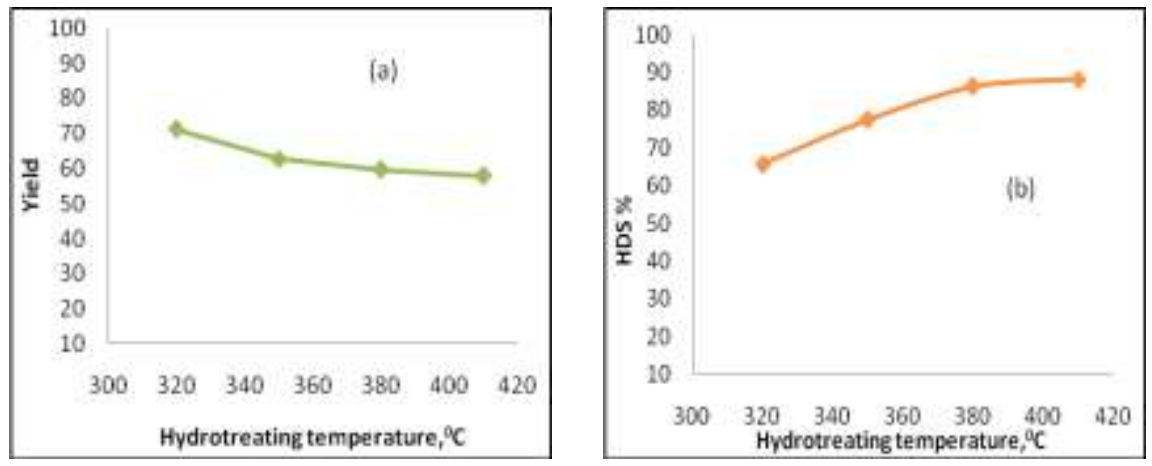

Fig. 6. Effect of hydrotreating temperature on (a) yield, (b) HDS.

Egypt. J. Chem. 58, No.6 (2015) 

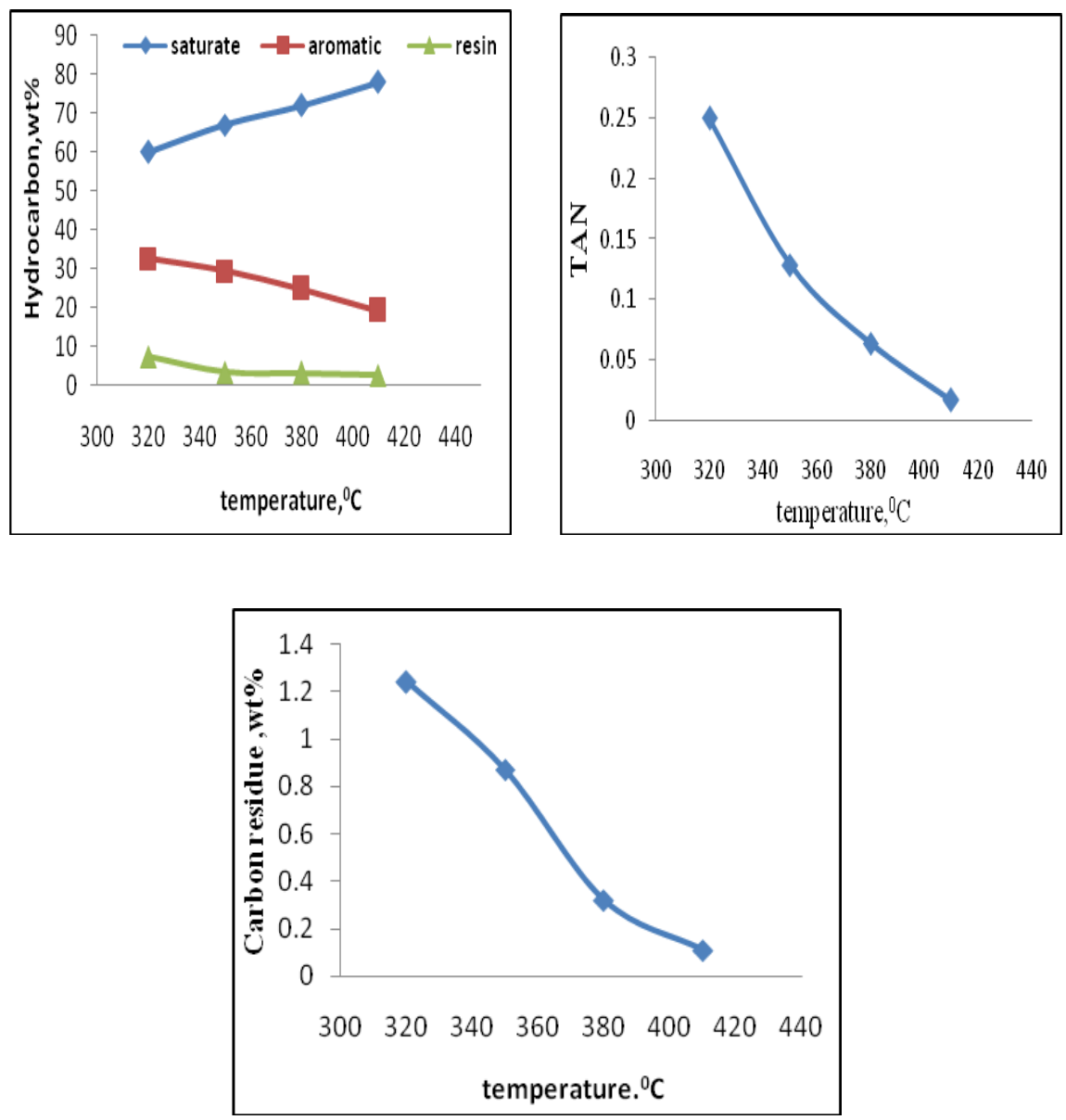

Fig. 7. Effect of hydrotreating temperature on (a) hydrocarbon (b) total acid number and (c) carbon residue.

2. Effect of hydrogen pressure : The results represented in Fig. 8 show that as the total hydrogen pressure increased from 30 to 70 bar, a great change in the yield and quality characteristics of lube oils was observed, HDS increased from $61.4 \%$ to $84.2 \%$ and aromatic content was decreased from $33.5 \%$ to $25.5 \%$ at 30 to70 bar; this can be attributed to the increase of hydrogenation activity of the catalyst with increasing the total hydrogen pressure in addition to the increase of the saturation activity and reduction of coke formation ${ }^{(18)}$.

3. Effect of liquid hourly space velocity : The effect of liquid hourly space velocity on the quality characteristics of the raffinate was studied at $350{ }^{\circ} \mathrm{C}$ and at hydrogen pressure of 50 bars which is represented through Fig. 9 and 10. 

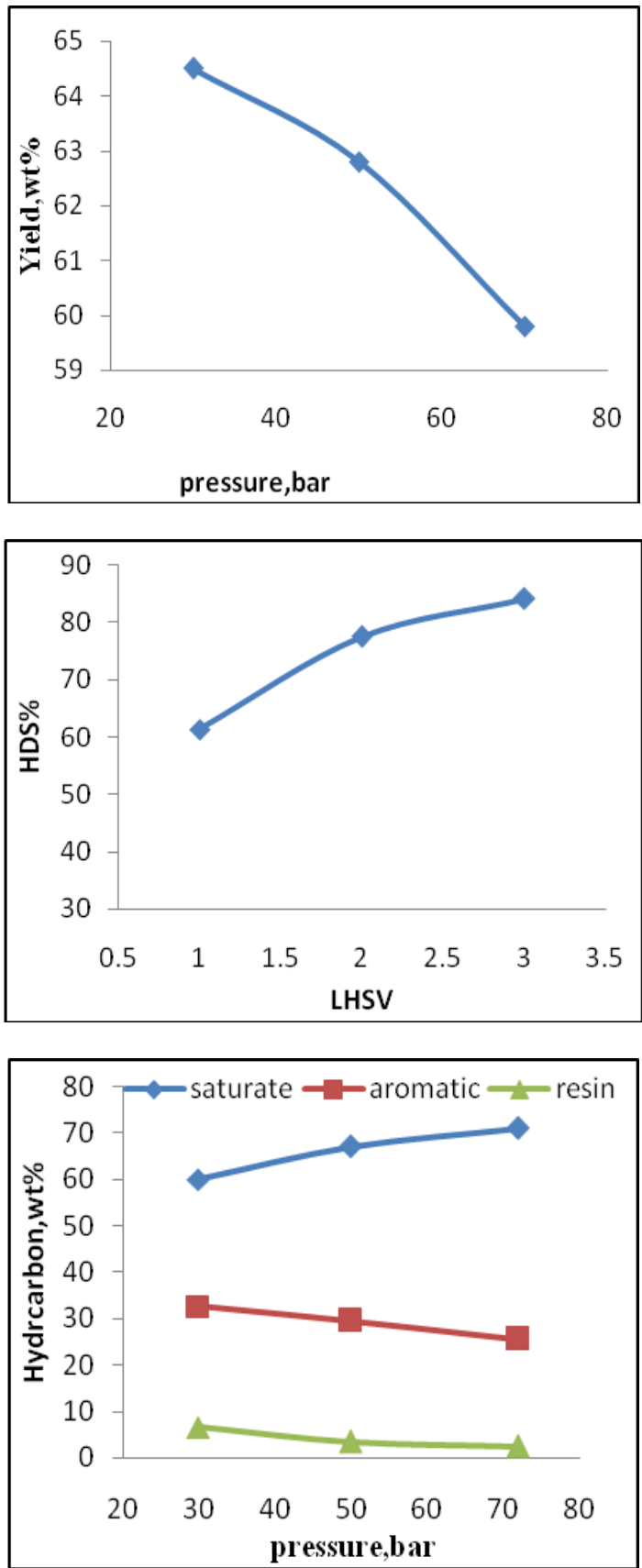

Fig. 8. Effect of hydrotreating pressure on (a) and (c) hydrocarbon.

Egypt. J. Chem. 58, No.6 (2015) 

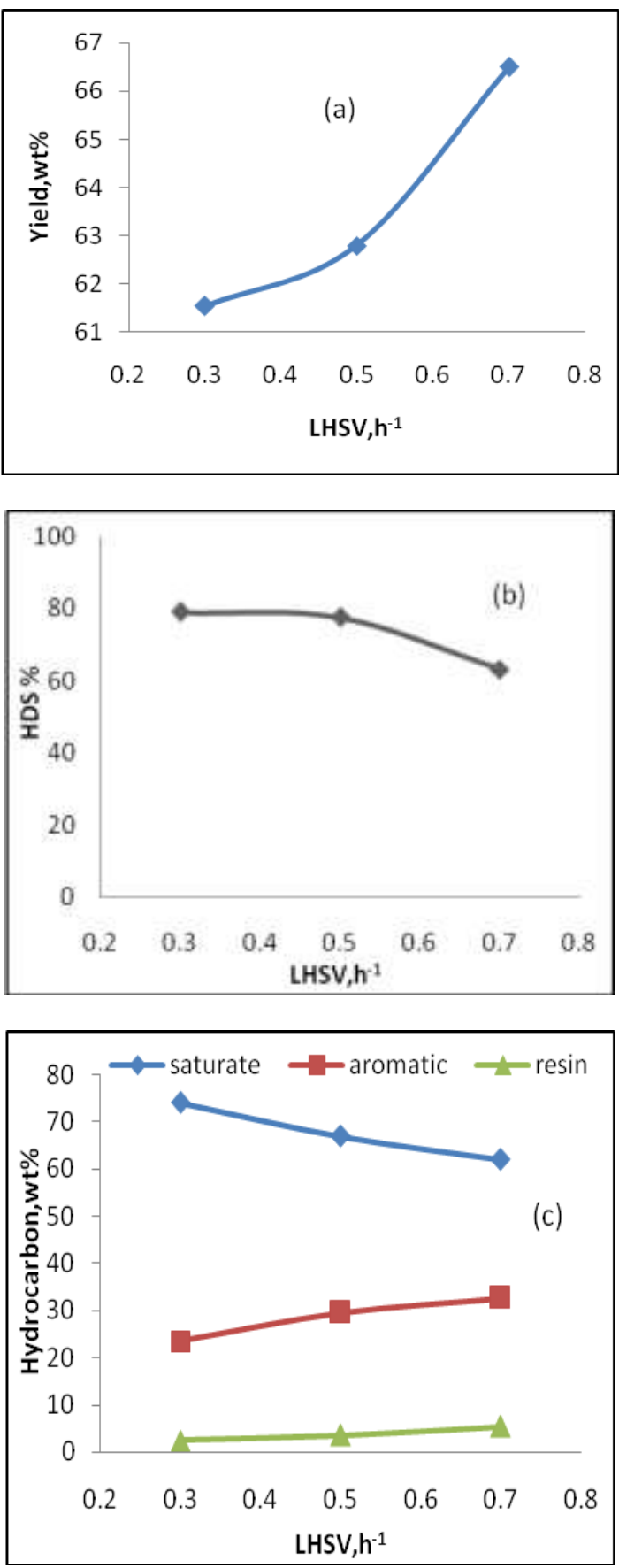

Fig. 9. Effect of hydrotreating LHSV on (a) yield (b) HDS, (c) hydrocarbon structure.

Egypt. J. Chem. 58, No.6 (2015) 

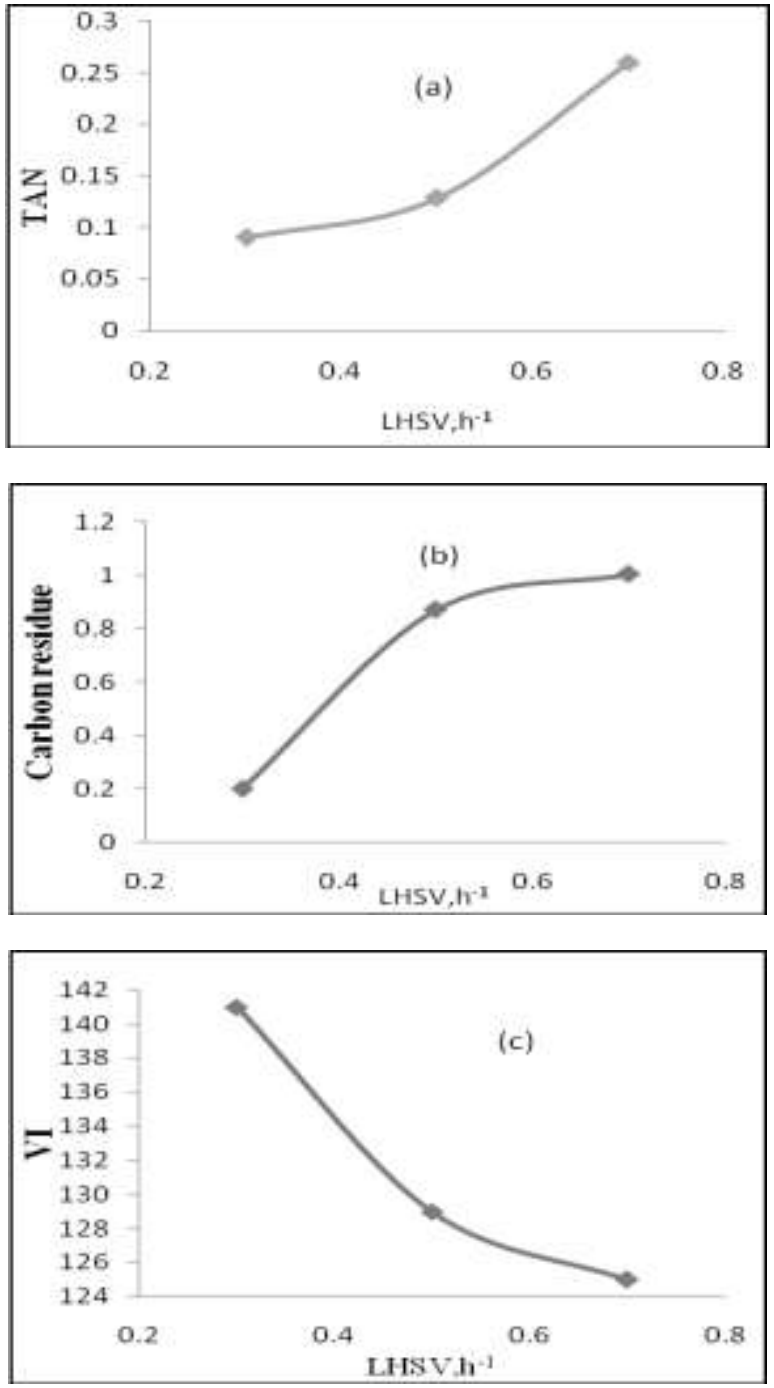

Fig. 10. Effect of LHSV on (a) total acid number, (b) carbon residue and (c) viscosity index.

Evidently, by increasing liquid hour space velocity from 0.3 to 0.7 , the hydrotreatment activity of the catalyst decreased due to the decrease in contact time between the reacting waste lube oil molecules and the active sites of the catalyst. It was found that the yield, density, refractive index and total aromatic content increased while saturate and HDS activity of the catalyst was decreased. This can reflect that no improvement in the quality of waste lube oil was attained by increasing LHSV.

Egypt. J. Chem. 58, No.6 (2015) 


\section{Hydrodesulphurization activity of spent and rejuvenated catalyst}

Table 5 shows the catalytic testes carried out using both spent and rejuvenated catalyst (using $4 \%$ oxalic $+\mathrm{Fe}\left(\mathrm{NO}_{3}\right)_{3}$ at continuous modes) under the constant temperature, hydrogen pressure and liquid hour space velocity $\left(350{ }^{0} \mathrm{C}, 50 \mathrm{bar}\right.$, $0.5 \mathrm{~h}^{-1}$ ) respectively. The data indicate that the activity of catalyst is further decreased after 5 years due to carbonaceous and metallic deposition on the catalyst. It means that the surface area of the catalyst decreased with increasing these contaminants, i.e. pore plugging due to long operation ${ }^{(19)}$.

Table 5 shows the catalytic test results HDS activity by the rejuvenated catalyst increased to be 65.33 more than the spent, and aromatic content decrease from 32 to $30.5 \mathrm{wt} \%$ and saturate increase from 63.5 to $65.5 \mathrm{wt} \%$ indicating that the improvements in treated catalysts activity may be attributed to the formation of more Ni Mo S active phase. This phase is a result of the sulphiding of the $B$ $\mathrm{NiMoO}_{4}$ compound formed during the reoxidation treatment ${ }^{(20)}$.

Oxalic acid treatment improved the equilibrium HDS activity of the catalyst (nearly close to the equilibrium of fresh), the oxidized 4\%oxalic acid solution solvent approached the activity of the spent catalyst about $85 \%$ from the fresh catalyst ${ }^{(21)}$.

TABLE 5. Hydrotreating of waste lube oil using fresh, spent and rejuvenated catalysts.

\begin{tabular}{|l|c|c|c|}
\hline Catalyst Characteristics: & Fresh & Spent & Rejuvenated \\
\hline Yield, wt\% & 80.6 & 90.4 & 85.4 \\
Yield, wt\%(from WLO) & 62.8 & 70.5 & 66.6 \\
\hline Density, $70^{\circ} \mathrm{C}$ & 0.8654 & 0.866 & 0.863 \\
\hline Viscosity index & 129 & 120 & 124 \\
\hline Sulphur content, wt \% & 0.17 & 0.3 & 0.26 \\
\hline HDS \% & 77.33 & 60 & 65.33 \\
\hline Refractive index, $70^{0} \mathrm{C}$ & 1.4576 & 1.4599 & 1.45798 \\
\hline Pour point, ${ }^{0} \mathrm{C}$ & 3 & -3 & 0 \\
\hline Carbon residue & 0.87 & 1.16 & 0.98 \\
\hline TAN, mg KOH/ gm & 0.1285 & 0.2275 & 0.1456 \\
\hline ASTM color, unit & 2.5 & 5 & 3.5 \\
Hydrocarbon,wt\% & 67 & 63.5 & 65.5 \\
Saturate & 29.5 & 32 & 30.5 \\
Aromatic & 3.5 & 4.5 & 3.5 \\
Resin & & & \\
\hline
\end{tabular}




\section{Conclusions}

The used lube oil contains impurities such as metals, aromatic and carbonaceous materials that have carcinogenic effect and pollute environment. Solvent extraction process is used to regenerate used lube oil using NMP\& KOH $3 \mathrm{~g} / \mathrm{l}$ at different temperatures range from 50 to $70^{\circ} \mathrm{C}$, and solvent to feed ratio range from $1 / 1$ to $7 / 1$.

The physico - chemical properties were determined to select the optimum condition that gives good yield high quality. The results indicate that the best solvent to feed ratio and temperature is $5 / 1$ and $70^{\circ} \mathrm{C}$, respectively. The best raffinate was used as starting base material for producing lube oil via catalytic hydrogenation, using freshly $\mathrm{NiMo}_{\mathrm{Al}} \mathrm{O}_{3}$ catalyst.

The best conditions of hydrotreating to produce the high quality lube oil are (temperature $=350^{\circ} \mathrm{C}$, pressure $=50$ bar and LHSV $=0.5 \mathrm{~h}^{-1}$ ).

The optimum condition of hydrotreating applied to the extracted waste lube oil with rejuvenated and spent catalyst to compare (HDS) activity and the quality of product.

The result indicated the improvement of the quality of waste lube oil and HDS activity nearly approaches to that the fresh of the same type.

\section{References}

1. Al-Ghouti, M.A. and Al-Atoum,L.,Virgin and recycled engine oil differentiation: A spectroscopic study. J. of Env.Manag. 90, 187-195 (2009).

2. Foo, C.Y., Rosli, M.Y. and Tea,S.S., Modelling and simulation of usedlubricant oil rerefining. Second World Engineering Congress Sarawak, Malaysia, 22-25 July (2002).

3. Lu, L., Technico-economic evaluation of used rolling oil treatment between UCO module and conventional process in China TRITA LWR Degree Project 12-21 (2012).

4. Rahman, M.M., Siddiquee,T.A., Samdani, S. and Kabir, K.B., Effect of operating variables on regeneration of base-oil from waste oil by conventional acid-clay method. Chemical Engineering Research Bulletin, 12, 24-27 (2008).

5. Sherman, J.H., Removal of transition metals from motor oil usingion exchange resins. J. Environ. Technol. 14 (11), 1097-1100 (1993).

6. Chementator, A., Solvent extraction process recycles waste oil. Chem. Eng. 103, 19-19 (1996).

7. Saunders, J., Used oil refining revolution. Lubricants. Lubricants World, 6, 20-24 (1996). 
8. Elbashir, N.O., Al-Zahrani, S.M., AbdulMotalib, M.I. and Abasaeed, A.E., Extraction parameters for recycling of used lubricating oils. J. Chem. Eng. and Proc. 41, 765-769 (2002).

9. Elbashir, N.O., Al-Zahrani, S.M., Abdul Mutalib, M.I. and Adnan, R., Recycling of used lubricating oil by solvent extraction. A guideline for single solvent design. Proceedings of RSCE97, Johar, Malaysia, 1, 420-427 (1997).

10. Reis, M.A. and Jernimo, M.S., Waste lubricating oil re-refining by solvent extraction flocculation: A scientific basis to design efficient solvents. Ind. Eng. Chem. Res. 27, 1222 -1228 (1988).

11. Hamad, A., Al-Zubaidy, E. and Fayed, M.F., Used lubricating oil recycling using hydrocarbon solvents. J. Envi. Manage .74, 153 -159 (2005).

12. Lukic, J., Orlovic, A., Spiteller, M., Jovanovic, J. and Skala, D., Rerefining of waste mineral insulating oil by extraction with N-methyl-2-pyrrolidone. Separation and Purification Technology, 51 (2), 150-156 (2006).

13. Abdel-Jabbar, N.M., AlZubaidy, E.A.H. and Mehrvar, M., Waste lubricating oil treatment by adsorption process using different adsorbent. World Academy of Sciences, Engineering and Technology, 62, 9-12 (2010).

14. Durrni, H.A., Panhwar, M.I. and Kazi, R.A., Determining efficient solvent extraction parameters for re-refining of waste lubricating oils. Mehran University Research Journal of Engineering \& Technology, 31 (2), 265-270 (2012).

15. Rincon, J., Canizares, P. and Garc' 1a, M.T., Regeneration of used oil by ethane extraction. J. Supercritical Fluids, 39, 315-322 (2007).

16. Eman, A.E. and Abeer, M.S., Re-refining of used lube oil, 1- by solvent extraction and vacuum distillation followed by hydrotreating. Petroleum \& Coal, 55 (3), 179-187 (2013).

17. Pass, F.J., Poll, H. and Schuster, J.F., $5^{\text {th }}$ World Petrol. Cong. Proc.; Sect. III, paper 32, 413 , New York (1959).

18. Gary, J.H. and Glenn, E.H., Petroleum Refining Technology and Economics; $4^{\text {th }}$ edition, Marcel Dekker, Inc.; New York, 287-302 (2001).

19. Ahmed, H.S. and Menoufy, M.F., New Trends in Hydroprocessing Spent Catalysts Utilization, Petrochemicals, Dr Vivek Patel (Ed.) in Croatia, 249-258 (2012).

20. Madeja, A.S., Kinetics of Mo, Ni, V and Al leaching from a spent hydrodesulphurization catalyst in a solution containing oxalic acid and hydrogen peroxide. Journal of Hazardous Materials, 186, 2157-2161 (2011).

21. Sadeek, A.S., Ahmed, H.S., El-Shamy, E.A., El Sayed, H.A. and Abd El Rahman, A.A., Hydrotreating of waste lube oil by rejuvenated spent hydrotreating catalyst. Egyptian Journal of Petroleum , 23, 53 -60 (2014). 


\section{إعادة تدويز الزيوت المستعملة باستخدام المذيبات والمعالجة الحفزية بالثهيدروجين}
حسين عبد العزيزالسيا ، اباء عبد المنعم الثـامي ، هلى سيل احمد و اسماء احمد عبدالرحمن
قسم التكرير - معهد بحوث البترول ـحي الزهور - مدينة نصر- القاهرة -

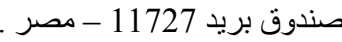

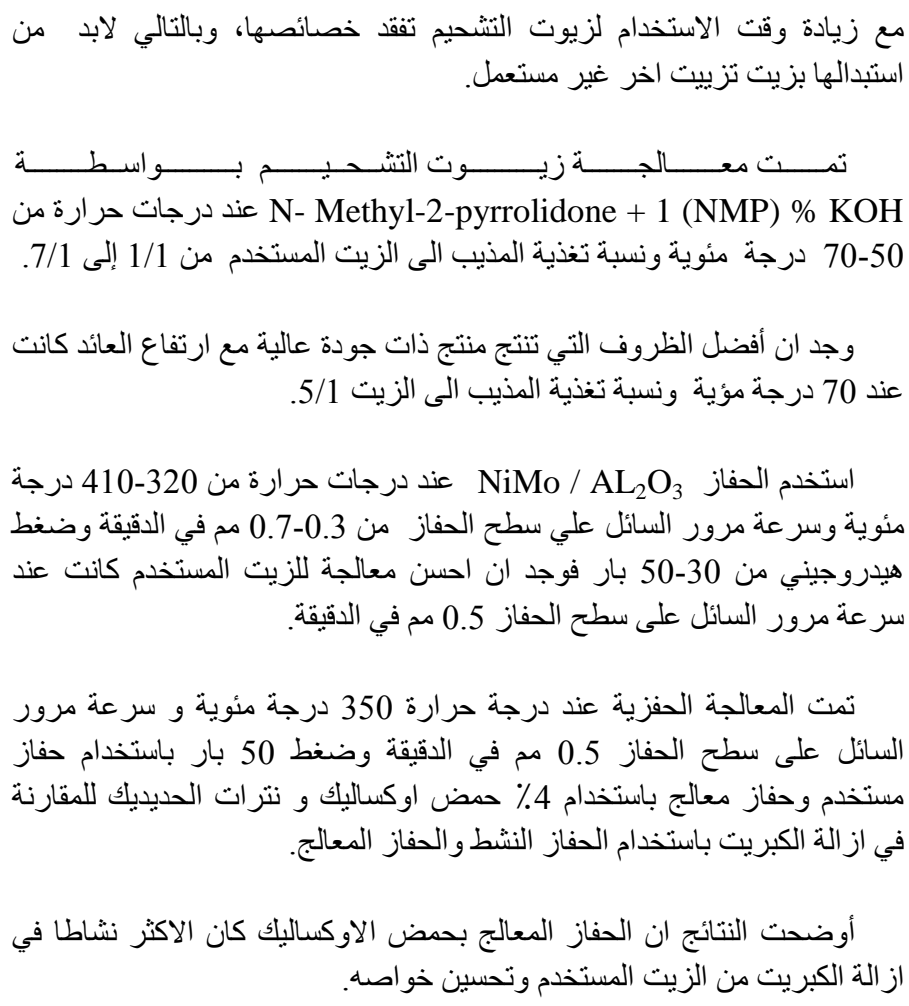

